\title{
Aproximações entre o conceito de uso de si e a teoria da mais-valia de João Bernardo'
}

\author{
Moacir Fernando Viegas ${ }^{2}$ \\ Universidade de Universidade de Santa Cruz do Sul (Santa Cruz do Sul, RS)
}

\begin{abstract}
As investigações baseadas no conhecimento ergológico demonstram que a atividade desenvolvida pelos trabalhadores não se reduz a uma perspectiva heterônoma, constituindo, diferentemente, iniciativas que configuram práticas e representações sociais originais. Conceitos como debate de normas e uso de si expressam como as relações sociais vividas no trabalho são perpassadas por embates de práticas e ideias numa permanente negociação do ser social. Porém, em que pese essa discussão revele que a experiência do trabalho vai além do econômico, ela não dispensa a consideração do mesmo, na medida em que é nesse contexto que ocorrem a disputa pelo uso de si e os debates de normas. Nosso propósito neste artigo é discutir as aproximações entre, de um lado, a categoria da maisvalia na teoria de João Bernardo, entendida como relação social contraditória em que os trabalhadores lutam por apropriar-se do produto do seu trabalho e os capitalistas buscam apropriar-se da produção dos primeiros, e, de outro, os conceitos de debate de normas e valores e de uso de si. De certa forma, nos propomos um questionamento da teoria ergológica no sentido de trazer contribuições à mesma, com vistas a uma abordagem interdisciplinar e omnilateral das práticas sociais educativas experienciadas nas relações de produção.
\end{abstract}

Palavras-chave: Uso de si, Debate de normas, Mais-valia, Ergologia.

Approximations between the concept of use of self and the theory of value of João Bernardo

The investigations based on the ergologic knowledge show that the activity developed by workers is not reduced to a heterogeneous perspective, building, differently, initiatives which set practices and original social representations. Concepts as debate of rules and the use of self express how the social relations lived at work are pervaded by conflicts of practices and ideas in a permanent negotiation of the social being. However, regarding this discussion, it shows that the experience at work goes beyond the economic issue, it does not exclude it, as it is in this context that happens the argument for the use of self and also the debate of rules. Our intention in this article is to discuss the approximations between, in one hand, the category of value which is understood as a contradictory social relation, in which the workers fight to take ownership of the product of their own work and the capitalists fight to take the advantage over what they make, and, in the other hand, the debate of rules and values and use of self concepts. In some way, we propose ourselves a question about the ergologic theory on bringing contributions to it, focusing on an interdisciplinary and omnilateral approach of the experienced social practices in the relations with the product.

Keywords: The use of self, Debate of rules, Value, Ergology.

\section{Introdução: como e por que os homens fazem história na atividade de trabalho}

Os homens fazem a sua própria história, mas não a fazem segundo a sua livre vontade; não a fazem sob circunstâncias de sua escolha e sim sob aquelas com que se defrontam diretamente, legadas e transmitidas pelo passado.

O 18 de Brumário de Luís Bonaparte (Marx, 1978, p. 17).

$\boldsymbol{E}^{\mathrm{m}}$ mbora essas palavras de Marx tenham sido mais comumente utilizadas para ressaltar o peso das determinações sociais da ação humana, ou seja, a força da estrutura econômica, como algo que heterodetermina as práticas sociais, elas podem ser entendidas também ressaltando o polo oposto, ou seja, são os homens que fazem a sua própria história. História que não é feita

1 Este artigo constitui resultado dos estudos realizados no Estágio Pós-Doutoral, cujo projeto teve como título "A educação nas relações de produção: aspectos subjetivos da formação dos trabalhadores na economia informacional" (2011-2012), no Departamento de Psicologia da Universidad Autónoma de Barcelona (Espanha), com bolsa da Capes, sob supervisão de Josep M. Blanch. Parte dos estudos foi realizada no Instituto de Ergologia da Universidade de Provence, sob orientação de Yves Schwartz.

2 Doutor em Educação. Professor do Departamento de Educação e do Programa de Pós-Graduação em Educação da Universidade de Universidade de Santa Cruz do Sul. Linha de pesquisa: Educação, Trabalho e Emancipação. 
num momento e num lugar determinado às expensas de outros lugares e tempos nos quais a história estaria ausente. Posto que é a ação humana que faz história e essa ação ocorre em todos os lugares, tempos e instituições, a história, a transformação da natureza e dos próprios homens, não tem um lugar e um tempo privilegiado para ocorrer.

Do ponto de vista do marxismo, ${ }^{3}$ a transformação da natureza e dos próprios homens ocorre pelo trabalho, que ocupa, assim, um lugar central nesse fazer história. Mas como a história é feita na atividade de trabalho? Na Ideologia Alemã, Marx e Engels afirmam que é necessário partir da consideração das bases materiais e de sua modificação pelos homens ao longo do tempo. A primeira necessidade humana é a necessidade de sobrevivência, para o que os homens devem organizar-se entre si e com a natureza e então produzir. Essa "determinada atividade", ao produzir as condições de sobrevivência, é uma forma dos seres humanos exprimirem a sua vida: "como exprimem a sua vida, assim os indivíduos são. Aquilo que eles são coincide, portanto, com a sua produção, com o que produzem e também com o como produzem. Aquilo que os indivíduos são depende, portanto, das condições materiais da sua produção" (Marx \& Engels, 1984, p. 15). Desse modo, é na atividade de trabalho, por meio da transformação da natureza e de si próprios, que os homens fazem história.

$\mathrm{Na}$ ergologia, a compreensão de que a ação humana possui um caráter histórico passa pelo entendimento do conceito de experiência (ou atividade, como mais recentemente o conceito vem sendo denominando). Para Schwartz, o trabalho é uma experiência de humanização. A permanente modificação das condições materiais de produção está relacionada com a própria natureza humana, que busca sempre, e independentemente das condições encontradas, uma ação que realize de algum modo a totalidade do ser. Para desenvolver esse conceito, o autor apoia-se em Canguilhem, para quem, nas palavras de Schwartz, "a vida pode ser definida através da atividade que está em luta permanente com 'a inércia e a indiferença'. Não somente o contrário da inércia, mas uma luta contra a inércia” (2007, p. 122).

Seguindo o pensamento de Canguilhem, o autor afirma que a tendência do trabalhador de confrontar sua história com o ambiente natural e social "pode ser vista como uma expressão da vida humana enquanto tal, na sua manifestação global, unificada e 'sintética'... Ela é uma atividade que se enraíza no esforço espontâneo vivente para dominar o meio e organizá-lo segundo seus valores" (Schwartz, 2007, p. 128). A experiência no trabalho é, assim, para a ergologia, um locus onde o trabalhador tenta reintegrar, a partir das condições em que se encontra, a unidade do seu ser, o que lhe confere, por consequência, um caráter enigmático advindo das numerosas formas como pode desenvolver sua experiência e das escolhas do uso de si que venha a fazer (Schwartz, 2011). Para o autor,

Toda forma de atividade em qualquer circunstância requer sempre variáveis para serem geridas, em situações históricas sempre em parte singulares, portanto escolhas a serem feitas, arbitragens - às vezes quase inconscientes - portanto, o que eu chamo de "usos de si", "usos dramáticos de si" (Schwartz, 1996, p. 151, grifo do autor).

Desse modo, o trabalhador não é passivo diante das normas que antecedem a realização do trabalho expressas, por exemplo, nos protocolos. A total heterodeterminação das normas de ação, seja qual for o paradigma produtivo, é "invivível", pois resultaria na ausência de vida e de atividade: "o meio é sempre em algum grau infiel, inantecipável" (Schwartz, 2011, p. 59). Como afirma Cunha (2007), esse fato implica que a atividade de trabalho seja uma "situação histórica sempre singular" (p. 5).

3 Há certamente muitos marxismos. Para resumir nosso pensamento, o que buscamos seguir aqui é o marxismo heterodoxo. Essa concepção costuma dar maior valor às práticas sociais dos trabalhadores do que o marxismo ortodoxo, em que o que conta para a transformação social são as práticas dos dirigentes intelectuais e políticos. Tragtemberg (1981) define o marxismo heterodoxo como “uma leitura de Marx não regida pelos moldes 'ortodoxos' definidos pelo chamado 'marxismo-leninismo' ou 'marxismo-leninismotrotskismo"” (p. 7). 
Esse impulso para a realização da totalidade do ser em todas as atividades humanas, Sennett (2008) busca no trabalho do artífice: o "artesanato designa um impulso humano duradouro e básico, o desejo de realizar bem uma tarefa" por si só, sem outras motivações, já que isso constitui sua recompensa: "em sua mente, os detalhes do trabalho cotidiano se conectam com o produto final; o trabalhador controla suas ações no trabalho; o trabalho se relaciona com a liberdade de experimentar" (p. 22). O autor apresenta as diversas formas como os trabalhadores, mesmo os que realizam as atividades mais simples, procuram deixar marcas de si próprios nos trabalhos que realizam. Para ele, esse impulso não pertence apenas ao trabalho qualificado do artífice medieval e sim, "faz parte da realização de qualquer trabalho humano, como o do programador de computador, do médico ou do artista" (Sennet, 2008). ${ }^{4}$

O sonho taylorista era retirar do trabalhador qualquer iniciativa e possibilidade de ação autônoma na produção econômica, isso que Schwartz (2010) chama de tentativa de "neutralização do histórico", num sentido, inclusive, de interdição da ação operária. Mas é impossível não haver essa ação, assim como separar humanização e ação. Portanto, é impossível não haver história na atividade humana.

O objetivo do presente trabalho é estabelecer aproximações entre a teoria da relação social de mais-valia, conforme apresentada por João Bernardo, e a ergologia, especialmente pelos escritos de Yves Schwartz, fundador dessa abordagem. Consideramos que, dada a complexidade dessas teorias e o estágio inicial em que se encontram nossos estudos, trata-se de uma primeira tentativa de aproximação. Pensamos que a validade desse esforço está relacionada à necessidade de pensar uma teoria que permita ver as possibilidades emancipatórias das lutas dos trabalhadores que ocorrem nos locais de produção, a nosso ver frequentemente ignoradas na produção intelectual. Acreditamos também que a discussão pode contribuir para subsidiar as teorias empenhadas na compreensão desse fenômeno no que se refere ao entendimento das relações entre o econômico, o político e o cultural.

Da teoria da mais-valia, destacamos, além do conceito central formulado por Bernardo, outros aspectos dele decorrentes, como as formas de lutas dos trabalhadores. Da parte da ergologia, trabalhamos principalmente com os conceitos de atividade, debate de normas e uso de si. O eixo principal para estabelecermos as aproximações é o fato de ambas as teorias conceberem as práticas dos trabalhadores nos locais de produção como relações sociais entre práticas e concepções de mundo contraditórias e, por isso, caracterizadas pela abertura às possibilidades de realização humanas.

\section{A teoria social da mais-valia como capacidade de ação}

A relação social econômica e conflito essencial do capitalismo é a mais-valia, assim formulada por Bernardo (1991): "o tempo de trabalho incorporado na força de trabalho é menor do que o tempo de trabalho que a força de trabalho é capaz de despender no processo de produção" (p. 15). A mais-valia está não apenas no fulcro da vida social econômica, mas expressa também a contradição essencial do sistema, por meio da qual podemos definir as

\footnotetext{
4 De diferentes maneiras, outras teorias têm ressaltado o caráter criativo e transformador da ação humana. Alcover de La Hera (La Hera, Íñigo, Mazo \& Bilbao, 2004), por exemplo, discutindo o que para ele constituem os referenciais básicos da Psicologia do Trabalho, comenta que "entender a conduta humana como mera resposta a uma situação estimular é empobrecê-la radicalmente. As pessoas elaboram a informação contida na situação estimular, interpretam essa situação, o fazem, além disso, com referências e interpretações prévias compartilhadas com outras pessoas, influídas por concepções globais da realidade - culturais, ideológicas - e emitem uma resposta que, por sua vez, vai ser interpretada por si mesmos e por outros. (...) A forma de abordar o pensamento está em analisar como as pessoas captam essa informação, como armazenam, a processam e a recuperam, e como a utilizam” (p. 214). Na psicodinâmica do trabalho, Gernet e Dejours (2009) afirmam que "o exercício do trabalho é acompanhado inevitavelmente da confrontação ao real, quer dizer, a isso que se faz conhecer àquele que trabalha por sua resistência à dominação, e impulsiona o sujeito a pensar e agir de outra forma que a organização do trabalho previu” (p. 27).
} 
classes sociais, que ocupam na relação os polos opostos da relação social. No centro da relação encontra-se o movimento que articula os dois polos e que lhes dá vida, "a ação da força de trabalho, a sua capacidade de trabalhar" (Bernardo, 1991, p. 15). É a ação da força de trabalho que dá vida ao capital morto, que vivifica o acúmulo de capital estagnado nos bens já produzidos:

Os elementos representativos do capital constante são trabalho morto enquanto permanecerem exteriores ao elemento ativo das relações sociais, enquanto a força de trabalho em ação não os inserir de novo no processo de produção da mais-valia. $\mathrm{O}$ mecanismo da exploração, sinônimo do trabalho vivo no seu processo, mantém como capital toda a sociedade e todos os elementos materiais que a corporalizam... Assim, no centro do capitalismo, sustentando-o como relação social em reprodução, encontra-se a força de trabalho entendida enquanto capacidade de ação (Bernardo, 1991, p. 19).

Marx entendia a ação como uma prática material, algo inédito na época, quando predominava a ideia de ação como processo mental. Para Bernardo, essa última compreensão escamoteia a ação enquanto processo prático de produção material. Segundo o autor, essa tendência é ainda predominante nas concepções acadêmicas a nas ideologias imperantes na vida cotidiana. Isso acarreta e, ao mesmo tempo, expressa a desvalorização social que sofre a prática material: "não se reconhece a força de trabalho em qualquer ação como categoria conceitual, porque os trabalhadores não assumem nenhuma posição de poder na sociedade" (Bernardo, 1991, p. 51). E quando a prática material é vista na esfera ideológica como uma categoria própria, reflete a tentativa dos trabalhadores apoderarem-se da totalidade do movimento social.

A ação da força de trabalho é eminentemente coletiva. Por uma parte, isso tem a ver com a interdependência entre as várias etapas da produção, de modo que os processos produtivos não podem ser vistos em seu isolamento. Por outra, nessa interdependência, um dado processo de trabalho só se realiza como capital no momento em que for vivificado pelos processos seguintes. Assim, podem-se apresentar os casos de trabalhadores individuais, ou mesmo grupos, somente na medida em que dependentes da ação coletiva dos trabalhadores.

Uma das características essenciais desse movimento dos trabalhadores é o desapossamento. São eles que dão vida à produção, mas, ao mesmo tempo, são desprovidos do controle sobre o processo e da "possibilidade de se formar e se reproduzir independentemente" (Bernardo, 1991, p. 15). Esse controle e essa possibilidade pertencem ao capitalista, a partir do momento em que ele adquiriu o direito de uso da força de trabalho. $\mathrm{O}$ que expressa o quão conflitante é essa relação é o fato de que "são os trabalhadores os que executam os raciocínios e os gestos necessários à produção, mas a todo o momento os capitalistas lhes retiram o controle sobre essa ação, integrando-a no processo produtivo em geral e subordinando-a aos seus requisitos" (Bernardo, 1991, p. 16), um processo de desapossamento que se renova dia após dia. Ao mesmo tempo, existe a luta pela reapropriação desse controle. Para Bernardo (1991), aí reside "o âmago da problemática da mais-valia" (p. 16).

As lutas pelo controle da ação, por parte dos trabalhadores, podem ser entendidas, na perspectiva ergológica, como a luta pelo uso de si, conceito que passamos a expor a seguir.

\section{As (re)normalizações e o conceito de uso de si}

Pensamos que o conceito de uso de si é, em grande parte, decorrência da compreensão de que a atividade de trabalho é, para o trabalhador, um lugar de expressão de sua humanidade, de modo que é impossível o trabalho ser apenas execução e, desse modo, não haver história 
nessa ação. Há um impulso para a realização daquilo que é humano, um desejo de expressar-se enquanto ser social inerente à ação. Assim, há sempre uma distância (écart) entre aquilo que foi produzido e aquilo que é realizado em ato no trabalho, uma característica universal da produção econômica. Além disso, apesar da possibilidade de certa antecipação da atividade, essa antecipação é parcial, pois a atividade demanda do trabalhador certo grau de iniciativa para que o trabalho seja realizado. E, ao ter de agir, é impossível que o trabalhador não entre com o seu ser.

Conceitos que no nosso entender são essenciais para a compreensão do uso de si são os de normalizações e renormalizações, e o debate de normas daí decorrente, mais amplos do que trabalho prescrito e trabalho real, desenvolvidos pela ergonomia francesa. Esses últimos são conceitos mais "fixados", pois a qualidade essencial da prescrição é justamente sua imutabilidade, enquanto o realizado refere-se apenas ao que realmente foi feito. Tais conceitos, a nosso ver, em que pese sua inequívoca pertinência, excluem o movimento inerente à atividade, assim como a ergologia propõe.

As normalizações são as normas e os regulamentos anteriores à realização do trabalho e compreendem também as normas instituídas pelo coletivo dos próprios trabalhadores. Constituem uma espécie de sedimentação provisória daquele conhecimento anterior à realização do trabalho, em parte sistematizado nas normalizações administrativas, em parte não sistematizado nas normas instituídas pelos trabalhadores. As renormalizações são uma condição sine qua non para que o trabalho aconteça. Para que haja a iniciativa do trabalhador, para que ele realize o desejo, de algum modo, de deixar a sua marca, o que é também uma forma de resistir à domesticação, ele precisa expressar-se, o que ocorre por meio tanto do corpo quanto da mente, na medida em que "a história da pessoa está profundamente engajada no que ocorre" na atividade (Schwartz \& Mencacci, 2008, p. 10). As renormalizações ocorrem num debate com as normas antecedentes (o que remete às condições materiais encontradas), e isso, para os autores, envolve uma dimensão bem maior do que o trabalho prescrito, insuficiente para o enquadramento da ação.

É por isso que essas duas dimensões, normalizações e renormalizações do trabalho, ocorrem de maneira inseparável. A primeira está ligada mais à necessidade de corresponder às normas antecedentes, o que configura uma "anulação" ou tentativa de anulação do histórico, mais sedimentada (as condições materiais encontradas) do que em movimento, mas da qual não se consegue escapar, e que corresponde ao que Schwartz chama de uso de si pelos outros. A segunda diz respeito à impossibilidade de anulação do histórico, à inevitável "infiltração do histórico no protocolo prescrito" (Cunha, 2007, p. 5), na medida em que, quando age, o corpomente expressa, seja pelo desejo ou pela necessidade da própria concretização da ação, todo um patrimônio cultural, um processo de hominização que o autor chama de uso de si por si mesmo. Nele, "é a pessoa que reinventa certa maneira de fazer, de viver, de sobreviver com os outros" (Schwartz \& Mencacci, 2008, p. 11).

Para Schwartz, ao adentrar num lugar de trabalho, vemos que existe uma série de normas que antecedem a realização do trabalho pelos trabalhadores, pertencentes ao âmbito da organização, do organograma, dos procedimentos etc., que são fixadas. Há também normas antecedentes instituídas pelos próprios trabalhadores, normas do grupo, ou seja, "renormalizações coletivas estabilizadas". Estas se diferenciam daquelas geradas pela administração, porque não são escritas "e são criadas a partir da atividade de trabalho", dos problemas surgidos nesse âmbito. Há continuidades e descontinuidades entre esses tipos de normas. Já a renormalização "é tudo que eu faço no momento em que, eu, pessoa singular, com meus próprios antecedentes, minhas próprias relações com esse universo de normas antecedentes, eu entro num lugar de trabalho e eu trabalho, é isso que eu chamo de uso de si por si” (Schwartz \& Mancacci, 2008, p. 13). 
Quando, requisitado pela atividade de trabalho, esse patrimônio histórico entra em ação, recursos muito mais amplos do que os que são demandados e explicitados de forma imediata entram em funcionamento, pois é o indivíduo como ser social que é chamado a agir. Para o autor, isso faz que os processos produtivos e os conflitos sociais a ele inerentes sejam incompreensíveis sem a consideração do que ele chama de uma "espécie de ambiguidade entre uso de si por si e uso de si por outros" (Schwartz, 2000, p. 11).

Sem o conceito de uso de si, não se pode compreender também o recuo do taylorismo. Para o autor, em um determinado momento, tornou-se difícil gerir essa presença ambígua do uso de si por si mesmo e do uso de si pelos outros em cada ação do trabalhador (Schwartz \& Echternacht, 2007, p. 11), ou seja, a inevitável penetração do histórico frente à tentativa de enquadramento da atividade nas normas antecedentes.

É importante mencionarmos aqui o fato de que o recuo do taylorismo ocorre acompanhado justamente da incorporação de parte dessa dimensão mais criativa dos trabalhadores na produção. Como demonstram Womack, Jones e Roos (1992) numa ótima descrição do desenvolvimento do toyotismo, as transformações originadas nesse paradigma produtivo advêm da incorporação de conhecimentos historicamente escondidos pelos trabalhadores nas fábricas de produção em massa. É o que Gorz chama de "inversão parcial" da desqualificação da força de trabalho, que consiste na descoberta, pelos gestores capitalistas, de que a organização opressiva do trabalho, em função da resistência criada e expressa por indolência e hostilidade difusa, priva a empresa da inventividade e criatividade operárias, tendo como consequência enormes prejuízos (Gorz, 1984).

É necessário destacar, no entanto, que as formas como ocorre a incorporação das habilidades dos trabalhadores são testemunhas do conflito inerente a sua existência. As empresas não toleram que os trabalhadores tomem a iniciativa de reorganizar o processo produtivo. A expressão do ser do trabalhador é objeto de permanente tentativa de controle pelos capitalistas, mesmo que em sua totalidade isso seja impossível.

\section{Usos de si, mais-valia e lutas dos trabalhadores}

A partir daqui, devemos considerar que o trabalho não pode resumir-se à domesticação ou à alienação. É certo que o trabalhador nada dispõe a não ser de sua força de trabalho. Para trabalhar e sobreviver, ele precisa ceder o controle de sua força de trabalho ao capitalista, o que constitui uma separação entre ele e sua força de trabalho. Havendo a separação entre o indivíduo e seu trabalho, há, também, uma separação entre o indivíduo e tudo o que se refere a seu trabalho: o processo de trabalho, os produtos, sua natureza humana e os outros homens. A atividade de alienação é, assim, sobretudo, alienação de si mesmo: "se o produto do trabalho é alienação, a própria produção deve ser alienação ativa - a alienação da atividade da alienação" (Marx, 1979, p. 93).

O que afirmamos, no entanto, com apoio nas teorias que trazemos nesse estudo, é que esse processo não é isento de contradições. Para a ergologia, se a atividade é a relação entre uso de si pelos outros e uso de si por si mesmo, os quais carregam concepções de mundo e histórias diferentes, uma mais fixada, outra em movimento, está claro que a relação entre essas duas dimensões do trabalho não pode ser, em absoluto, convergente. Como consequência, a atividade de trabalho é o lugar de uma "tensão problemática, de um espaço de possíveis sempre a negociar" (Schwartz, 2000; Rosa, 1999, p. 3). Há duas ideias a destacar nessa frase. Uma refere-se à impossibilidade de antecipação total da atividade em decorrência das constantes contingências que atingem o ambiente de trabalho, que, por sua vez, demonstra a 
“infidelidade' do meio”. A outra é que, como já afirmado, esse espaço da produção econômica é um lugar de conflito, logo, também de negociação.

Tal conflito, a nosso ver, expressa as contradições da produção econômica capitalista, que tem a mais-valia como base das relações sociais. A contradição, como dissemos, está no cerne dessa relação social em que a força de trabalho articula os termos opostos, quais sejam, tempo de trabalho incorporado e tempo de trabalho despendido. A questão que permite ver essa relação como essencialmente aberta é o fato de a força de trabalho ser capaz de despender determinado tempo de trabalho na produção, mas este capaz de, como diz a expressão, ser indefinido. Como diz Bernardo (1991), "não implica nunca o grau exato em que [ela, força de trabalho] pode fazê-lo" (p. 71).

E isso na medida em que, como forma de valorização da sua força de trabalho, os trabalhadores lutam para incorporar o menor tempo possível à produção. Das formas de luta que Bernardo chama de passivas e individuais, como o desinteresse, o absenteísmo, o alcoolismo ou a dependência de entorpecentes, às ativas, como a sabotagem e

as várias gradações da ação coletiva, desde a diminuição em conjunto do ritmo de trabalho até a ruptura radical da disciplina de fábrica e a organização do processo produtivo consoante outros moldes e critérios [...] Por isso, os resultados do processo de exploração são irregulares, em grande parte imprevisíveis, fluidos (Bernardo, 1991, p. 71).

A luta central que ocorre no âmago no sistema produtivo é, assim, para Bernardo, uma luta pelo controle do tempo de trabalho. ${ }^{5}$

Schwartz (2000) concorda com a ideia de que, para o trabalho ser efetivamente realizado, os próprios prescritores não esperam que os trabalhadores ajam como autômatos ou mortos-vivos: "os ergonomistas sabem, hoje, perfeitamente que a estrita aplicação de prescrições conduziria ao desperdício, à insuficiência, senão à não valorização do trabalho morto" (p. 41).

Como dissemos, o impulso para a hominização, no qual é inerente a tentativa de realização, de expressão de si próprio, faz que o trabalho seja sempre um terreno de lutas sociais individuais e de classe. Para Schwartz, a atividade de trabalho é um espaço em que os interesses são negociados. Uma negociação entre o "ambiente histórico, social, gerencial, técnico", ou seja, as normas antecedentes, e "obrigações absolutas para se dar aqui e agora normas reprocessadas de trabalho e de vida" expressas no conceito de renormalizações (Schwartz, 2011, p. 58).

Ao renormalizar o que é protocolado, ao dar vida ao trabalho, os trabalhadores entram com seus valores no sentido de tentar criar um meio mais conforme a si mesmos. Para Cunha (2007), essas escolhas envolvem questões como qualidade versus rapidez, economia de si versus facilitar a vida coletiva e uma infinidade de outras, que resultam na necessidade de realizar "arbitragens, ponderações, critérios, engajamento" que se convertem, na prática, em "dramas do uso de si" (p. 10). Como diz Canguilhem (1947), "todo homem quer ser sujeito de suas normas" (citado por Schwartz, 2000, p. 48). Para Schwartz, tal negociação está na base de um "equilíbrio dinâmico", de modo que pode se perceber aí que, para a própria atividade produtiva acontecer, exige-se certo equilíbrio entre as forças antagônicas que lhe dão sustentação, em que, segundo o autor, "nenhum fim pode aniquilar totalmente o outro" (2000, p. 37).

Difícil não ver nessa compreensão a contradição inerente à luta de classes, visto que no "equilíbrio dinâmico", que pressupõe a existência do sistema, as classes sociais não podem viver uma sem a outra, o que implica uma permanente negociação entre práticas e representações sociais antagônicas. O fato de a atividade de trabalhar implicar práticas de renormalizações, um processo de humanização no qual os trabalhadores devem colocar sua vida no objeto de

5 Acrescentamos que, para o autor, os atuais métodos toyotistas não convencem os trabalhadores da identidade de interesses entre eles e os capitalistas, seguindo, portanto, a luta pelo controle do tempo. 
trabalho, significa que eles devem fazer escolhas (dramática do uso de si por si mesmo e do uso de si pelos outros): "gerir o aspecto encontro de encontros é gerir aquilo que os outros não geriram antes de nós, e, se você faz escolhas, forçosamente tem critérios a partir dos quais você faz essas escolhas. Trabalhar sobre essas escolhas é trabalhar sobre você mesmo" (2010, p. 44).

Questionando as clássicas divisões do trabalho, Schwartz afirma que as esferas manual e intelectual nunca se separam. Mesmo os trabalhos manuais mobilizam, por meio do corpo do trabalhador, o "suporte de uma história pessoal", uma massa de microapreciações, de microescolhas, de microjulgamentos, o que é especialmente claro no ramo dos serviços. A questão importante para nós são os critérios para essas escolhas. Em que medida esses podem ser considerados critérios individuais, humanizantes, e em que medida eles podem ser considerados também critérios de classe? Retomando a relação social de mais-valia e as várias formas de resistência dos trabalhadores, podemos considerar que os critérios estão relacionados, em maior ou menor grau, com os valores e concepções de mundo de classes sociais. Assim como um corpo é "suporte de uma história pessoal, uma 'massa' de microapreciações, de microescolhas, de microjulgamentos" (Schwartz, 2004, p. 59), esse corpo está ligado a critérios comuns de uma classe. Não queremos dizer aqui que o individual e o coletivo (a classe) se confundam a ponto de o último anular o primeiro. O que afirmamos é que ao menos parte dos critérios para essas escolhas, assim como dos valores, das concepções de mundo que subjazem as mesmas, são critérios de classe, e isso possui um fundamento econômico na relação social de mais-valia, nos conflitos entre tempo incorporado e tempo despendido.

Há uma politicidade no caráter do uso de si por si mesmo. Na medida em que implica renormalizações, e essas não estão dadas a priori, resulta em algo de imprevisível, o que faz que tanto as formas quanto a expressão do conteúdo dessas renormalizações tenham um caráter subversivo.

Os debates de normas não são apenas individuais, mas, sobretudo, coletivos:

Através deles, os protagonistas do trabalho não cessam de desfazer [...] os limites do exercício deles mesmos, dos horizontes de vida que essas divisões propõem ou impõem. Esses germes de transgressão instabilizam toda a divisão do trabalho, qualquer que seja ela. Toda a divisão do trabalho é sempre um resultado, mais ou menos instável, provisório, conflitual (Schwartz, 2004, p. 68).

O trecho citado é particularmente importante para discutir a subversão inerente à atividade de trabalho, e que remete à politicidade dos usos de si. $\mathrm{O}$ debate de normas expressa a oposição de concepções de mundo presentes, de um lado, na tentativa do capital de fazer um "uso dos outros" (os trabalhadores), convertido, do ponto de vista do trabalhador, no uso de si por outros e, de outro, no uso de si por si mesmo.

As lutas coletivas e ativas são, segundo Bernardo, a forma organizativa mais elevada que podem assumir as lutas dos trabalhadores. Nelas, eles atuam como um corpo único, e a ação de cada trabalhador repercute no comportamento de outro trabalhador. Nas formas de organização que expressam esse tipo de luta, os operários enfrentam a disciplina capitalista impondo ritmos próprios de trabalho, o que exige desde o princípio um conhecimento da produção e aponta ao mesmo tempo a tentativa de controle da mesma:

Ao organizarem-se, por iniciativa própria, em violação às normas, os trabalhadores estão a afirmar a vontade de decidirem o seu inter-relacionamento durante o trabalho e, portanto, manifestam uma tendência prática ao controle dos processos econômicos. É neste sentido que se trata de uma forma de luta. E é uma forma coletiva, pois um dado trabalhador dificilmente poderá modificar seu comportamento de trabalho sem o conjugar com a remodelação do dos colegas. É, portanto, uma forma ativa, pressupondo a iniciativa e a participação interessadas de todos os que colaboram (Bernardo, 1991, p. 50). 
Os trabalhadores, ao imporem formas de relacionamento coletivas e ativas, demonstram um conhecimento profundo das forças produtivas e da tecnologia capitalista, ao mesmo tempo que o decorrer do processo exige uma apropriação, cada vez maior, pelos mesmos, desse conhecimento, assim como a modificação dos próprios padrões de produção segundo as relações criadas no processo. Analisando essa questão a partir da ergologia, podemos afirmar que esse processo resultaria numa ruptura com a tentativa de enquadramento da atividade pelos gestores capitalistas, com as normas antecedentes assim como estão constituídas, ao mesmo tempo que abre a possibilidade de um mais amplo uso de si por si mesmo.

Para aumentar a produtividade, é necessário submeter os trabalhadores a cada vez mais complexas normalizações que visam enquadrar a atividade nos padrões exigidos pela gestão da produção. A essas tentativas de normalização os trabalhadores responderão com iniciativas necessárias à realização do trabalho, que implicam valores, concepções de mundo e desejos, distintos dos previstos nas normalizações. Ou seja, no aumento da produtividade, logo, da intensidade do trabalho, convergem o crescimento da mais-valia e a tentativa de instrumentalização do uso de si.

Para concluir, é importante dizermos que existe uma distinção entre os conceitos de mais-valia e o uso de si no que se refere à especificidade histórica de cada uma deles. A maisvalia expressa a relação social de exploração do trabalho realizado no sistema capitalista de produção, enquanto o uso de si é um conceito que remete ao trabalho como atividade industriosa na generalidade dos trabalhos no decorrer da história humana. O próprio Schwartz chama a atenção para uma distinção, em Marx, entre o conceito de trabalho como produção de valor em nossa época atual e o "trabalho em geral", ou seja, "movimento do trabalho útil em geral, abstração feita de toda marca particular que lhe pode imprimir uma ou outra fase do progresso econômico da sociedade" (Marx citado por Schwartz, 2011, p. 53). Para ele, mesmo no capitalismo, o trabalho segue tendo essa característica genérica, na medida em que, enquanto atividade industriosa, "jamais é puro encadeamento de normas, de procedimentos, pensados anteriormente e sem a pessoa que vai trabalhar, porque isso é simplesmente impossível e ao mesmo tempo muito difícil de ser vivido" (Schwartz, 2011, p. 64).

\section{Considerações finais: obstáculos a uma ampliação do uso de si por si mesmo}

Pensamos que a discussão aqui abordada insere-se no contexto da tensão entre adaptação e autonomia a que se refere Adorno. Afirma ele que, no projeto de formação do iluminismo, "havia um duplo propósito: obter a domesticação do animal homem mediante sua adaptação interpares e resguardar o que lhe vinha da natureza, que se submete à pressão da decrépita ordem criada pelo homem" (Adorno, 1996, p. 390). Essa tensão é, portanto, inerente à existência humana, necessária ao processo de socialização e dela não se pode fugir. Ocorre que, "nos casos em que a cultura foi entendida como conformar-se à vida real, ela destacou unilateralmente o momento da adaptação, e impediu assim que os homens se educassem uns aos outros" (Adorno, 1996, p. 390). Na história da formação, o peso sempre caiu mais para o lado da adaptação, o que leva à acomodação e ao conformismo. É o que ocorre também no trabalho.

Sennet (2008) afirma que o trabalho do artífice resulta em recompensa emocional, na medida em que ele trabalha com apoio numa "realidade tangível" que lhe permite orgulhar-se do que faz. Ocorre que a sociedade tem historicamente interditado a possibilidade dessas recompensas: 
em diferentes momentos da história ocidental, a atividade prática foi degradada, foi divorciada de objetivos supostamente superiores. A habilidade técnica foi desterrada da imaginação: a realidade tangível, questionada pela religião, e o orgulho do trabalho próprio considerado como um luxo (Sennett, 2008, p. 18).

Para o autor, em que pese o trabalho realizado na "nova economia" seja mais qualificado e exigente, "segue sendo uma tarefa dissociada". Em pesquisa que realizou, destaca que foram encontrados poucos técnicos "que acreditavam que seriam recompensados pelo fato de fazerem bem um trabalho, sem outra finalidade. $\mathrm{O}$ artesão moderno pode cultivar em seu fórum íntimo este ideal, mas, dado o sistema de retribuições, esse esforço será invisível" (Sennett, 2008, p. 29). Para ele, ao mesmo tempo que a nova economia incrementou a eficiência dos trabalhadores, os "descoraçonou".

Na compreensão de Oddone (1984), "ultrapassar a divisão do trabalho significa para os operários reapropriar-se do saber (pela reapropriação dos espaços de gestão, de poder, de decisão, de informação, etc.) dos quais eles têm sido privados pela divisão do trabalho” (p. 31). Ele afirma que não é possível separar as lutas políticas da competência profissional, ou seja, da experiência das capacidades de realização da atividade pelos trabalhadores.

Pensamos que uma maior amplitude da ação dos trabalhadores no que se refere à realização de suas vontades depende de uma ação coletiva. Ambas as teorias aqui analisadas valorizam, de diferentes maneiras, a ação individual de cada trabalhador. E ambas concordam que é uma forma de resistência, de opor-se à inércia, de vivificar práticas sedimentadas em processos de produção anteriores. Acreditamos que as ações individuais são também uma forma de "infiltração do histórico" no que é protocolado, e que, portanto, trata-se de um processo de humanização. Mas, como afirma Bernardo, as ações individuais podem ser assimiladas pelo capitalismo, que inclusive delas depende para que o trabalho ocorra.

É importante lembrar aqui a atitude dos capitalistas em relação às tentativas autônomas dos trabalhadores de assumirem o controle da produção. Gorz (1984) observa que, embora a nova economia dependa de maior iniciativa dos trabalhadores expressa na maior participação intelectual, as empresas só validam tais iniciativas quando as têm sob controle. Em ações em que são os trabalhadores quem tomam a iniciativa de realizar mudanças, colocando em cheque a disciplina e a hierarquia, as empresas costumam responder com repressão.

Nesse sentido, pensamos que é necessário que as lutas individuais, as formas de resistência, o uso de si por si mesmo, devem ultrapassar o âmbito individual para realizar todo seu potencial. Como afirma Oddone, uma transformação da situação atual é possível, desde que se acredite na possibilidade de ultrapassar a divisão do trabalho: a "condição de reconhecer, em suma, que a classe operária tem capacidade de operar dialeticamente a reapropriação daquilo de que ela foi despossuída pela divisão do trabalho" (1984, p. 30). Ao ultrapassar o âmbito individual, a tendência é que os critérios de escolhas feitas pelos trabalhadores sejam expandidos para o conjunto da produção. Os critérios individuais e um patrimônio histórico também individual continuariam existindo, mas aquilo que é comum nessas escolhas só pode realizar-se se puder ser efetivado coletivamente.

\section{Referências}

Adorno, T. (1996). Teoria da semicultura. Educação E̊ Sociedade, Campinas, 17 (56), 388-411.

Bernardo, J. (1991). Economia dos conflitos sociais. São Paulo: Cortez.

Cunha, D. M. (2007). Notas conceituais sobre atividade e corpo-si na abordagem ergológica do trabalho. 30 $\underline{a}$ Reunião Anual da ANPED, Caxambu. 
Gernet, I. \& Dejours, C. (2009) Évaluation du travail et reconnaissance. Nouvelle Revue de Psychosociologie. 8 (2), 27-36.

Gorz, A. (1984). O despotismo de fábrica e suas consequências. In Crítica da divisão do trabalho (pp. 79-90). São Paulo: Martins Fontes.

La Hera, A. de, C. M., Íñigo, D. M., Mazo, F. R. \& Bilbao, R. D. (2004). Introdución a la psicologia del trabajo. Madrid: McGraw-Hill.

Marx, K. (1978). O 18 Brumário: cartas a Kugelmann (4⿳⺈冂䒑 ed.). Rio de Janeiro: Paz e Terra.

Marx, K. (1979). Manuscritos econômicos e filosóficos. In E. Fromm (Org.), Conceito marxista do homem (Apêndice, pp. 85-222). Rio de Janeiro: Zahar.

Marx, K. \& Engels, F. (1984). A ideologia alemã: teses sobre Feuerbach. São Paulo: Moraes.

Oddone, I. (1984). La compétence professionnelle élargie. Société Française, 10, 28-33.

Rosa, M. I. (1999). Do governo dos homens: "novas responsabilidades" do trabalhador e acesso aos conhecimentos. Educação Ė Sociedade, 19 (64), 130-147.

Schwartz, Y. (1996). Trabalho e valor. Revista Tempo Social, 8 (2), 147-158.

Schwartz, Y. (2000). Trabalho e uso de si. Pro-posições, 5 (1), 34-50.

Schwartz, Y. (2004). La conceptualisation du travail, le visible et l'invisible. L'Homme et la société, 153 (2), 47-77.

Schwartz, Y. (2007). Un bref aperçu de l'histoire culturelle du concept d'activité. Activités, 4 (2), 122-133.

Schwartz, Y. (2010). A experiência é formadora? Educação Ė Realidade, 35 (1), 35-48.

Schwartz, Y. (2011). Qual sujeito para qual experiência. Tempus: Actas de Saúde Coletiva, 5 (1), 55-67.

Schwartz, Y. \& Echternacht, E. H. (2007). O trabalho e a abordagem ergológica: "usos dramáticos de si” no contexto de uma central de tele-atendimento ao cliente. Informática na Educação: Teoria E̊ Prática, 10 (2), 9-24.

Schwartz, Y. \& Mencacci, N. (2008). Trajectoire ergologique et gênese du concept d'usage de soi. Informática na Educação: Teoria Ė Prática, 11 (1), 9-13.

Sennett, R. (2008). El artesano. Barcelona: Anagrama.

Tragtemberg, M. (Org.) (1991). Marxismo heterodoxo. São Paulo: Brasiliense.

Womack, J., Jones, D. T. \& Roos, D. (1992). A máquina que mudou o mundo. Rio de Janeiro: Campus.

\section{Endereço para correspondência}

mviegas@unisc.br

Recebido em: 28/05/2012

Revisado em: 03/01/2013

Aprovado em: 27/02/2013 